\title{
Halliday's Functional Grammar: Philosophical Foundation and Epistemology
}

\author{
Nguyen Thi Tu Trinh, Phan Van Hoa \& Tran Huu Phuc \\ University of Da Nang, Vietnam \\ Correspondence email: trinhtoeic@gmail.com
}

\begin{abstract}
It is difficult to track the philosophy foundation and epistemology of systemic functional grammar (SFG) formulated by Halliday in the 1980s as this kind of grammar views language as a systemic resource for meaning. Besides, it has had global impacts on linguistics and flourished in contemporary linguistic theory. Anyone who is familiar with Halliday's work realizes that his SFG is an approach designed to analyze English texts. Halliday (1994: xv) explicitly states that "to construct a grammar for purposes of text analysis: one that would make it possible to say sensible and useful things about any text, spoken or written, in modern English." The aim of this study is not about the applicability of SFG to text analysis as many researchers and scholars do. Our efforts are made to clarify the philosophical foundation of Halliday's SFG. The paper presents on triangle: (i) language, mind and world; (ii) and empiricism in Halliday's SFG.
\end{abstract}

Keywords: Systemic functional grammar; philosophical foundation; epistemology; meaning and text.

\section{INTRODUCTION}

There have been considerable interests in SFG raised by Halliday since 1985. Many other linguists have been attracted by this new approach and major contributions are now being made by a new generation of SFG linguists. Particularly, SFG is employed to descriptions of language and typology. With the first attempt to describe English, Halliday started to analyze and describe Chinese in the 1940s and 1950s (Halliday 1956; 1959). Since then, a considerable number of languages such as Danish, French, German, Japanese, Korean, Thai, Vietnamese and many others (Mwinlaaru and Xuan 2016) have been described within SFG. They have made great contributions to empowering SFG theory. It is widely recognized that any linguistic theory must be well built on a firm philosophy foundation and epistemology and so is SFG. However, to my knowledge there is no in-depth analysis of the "grounding" of Halliday's SFG theory: philosophical ideas and epistemology in his work. Our attempts have been made to point out its "grounding": philosophical ideas and epistemology in SFG. It is hopeful that this study will explore more theory of SFG.

Halliday's SFG is so complicated, broad and philosophical that we cannot cover all matters in this single study. Therefore, in this study we just closely examine experimental metafunction and consider it in relation to philosophy.

\section{SOME PREVIOUS STUDIES}

Halliday (1985:192) describes language as a semiotic system, "not in the sense of a system of signs, but a systemic resource for meaning". This work is considered as a skeleton for his functional grammar theory.

Halliday and Matthiessen (2004) give an in- 
depth explanation of how human beings construe their experience of the world. The construction of experience is usually thought of as knowledge, represented in the form of conceptual taxonomies, schemata, scripts and others. The focus of the book is both theoretical and descriptive. The authors consider it important that theory and description should develop in parallel, with constant interchange between the two.

Bloor and Bloor (1995) present a short account of the analysis of English for those starting out with functional grammar. It sets out the tools and analytic techniques of Hallidayan grammar with clear explanations of terminology and illustrates these with examples from a variety of texts, including science, travel, history and literary sources.

Eggins (1994) introduces the principles and techniques of the functional approach to language. This approach views language as a strategic, meaning-making resource, systemic linguistics, and offers the analysis of authentic, everyday texts. In addition, it asks both how people use language to make meanings, and how language itself is organised to enable those meanings to be made.

In the late 20th century, namely the early 1960s, a new linguistic theory appeared and changed our viewpoints, critical thinking and reasoning about language. That is FG. FG has its roots from Prague school. The structuralist functionalism of the Prague school was the earliest functionalist framework developed in the 1920s. Hjelmslev, the Prague scholar, and Firth, the London scholar, are considered the fathers of functionalism; a new approach in linguistics. In the process, these linguists raise public awareness of functionalism in linguistics and inspire other scholars to do research, develop and expand functional approach. Halliday's SFG has been constructed and developed on the ground of Firth (1948) and Hjelmslev (1969) account. Halliday (2002:12) follows Hjelmslev and Firth in distinguishing theoretical from descriptive categories in linguistics. He argues that 'theoretical categories, and their inter-relations, construe an abstract model of language...they are interlocking and mutually defining".

Firth (1948) explains the three significant matters: prosodies, context and system versus structure. First, he points out that prosodies are features extending over stretches of an utterance. They include not only pitch, stress, tone and rhythm but also lip rounding or nasalization, when these are used to account for phonological restrictions, or to characterize grammatical structures. Second, he suggests conducting contextual analysis on four levels: 1) phonological analysis; 2) lexical and semantic analysis; 3) grammatical analysis and 4) the analysis of the context of situation. Finally, he focuses on figuring out the differences between system versus structure; that is, system is the theoretical representation of paradigmatic relations, contrasted with structure for syntagmatic relations. To my knowledge the two conceptions of Firth, concept of system and context of situation, are the most influential to Halliday and other younger functional linguists. In systemic theory the system takes priority: the most abstract representation at any level is in paradigmatic terms. Syntagmatic organization is interpreted as the realization of paradigmatic features.

Hjelmslev (1969) offers some general criteria for a theory of language, types of dependences, morphemes and phonemes, levels of language, langue and parole, neutralization and structuralist linguistic theory, glossematics. In his theory, he transforms Ferdinand de Saussure's structural linguistics into a rigorous formalistic theory of language. Its basic claim is that language is a general semiotic. structure of relations, and there are dichotomies of expression versus content, form versus substance, langue versus parole. Garvin (1954) states that "Hjelmslev's expression and content are roughly analogous to what linguists usually call form and meaning". Particularly, Hjelmslev (1953:69) defines that "a meta-(scientific semiotic) as a metasemiotic whose object semiotic is a scientific semiotic (a semiotic that enters as a plane into a semiotic is said to be the object-semiotic of that semiotic)". $\mathrm{He}$ also mentions many new terminologies in linguistics such as: glossematics, function, meta, ditchotomy, paradigm, analog and others, and these terminologies are widely used in Halliday functional grammar. As far as we can see, Hjelmslev's Prolegomena can serve as a skeleton for more far-reaching of Halliday's theory of functional grammar. Glossematics is considered 
as one of his most important contributions to linguistics and has had global impact.

\section{HALLIDAY'S PHILOSOPHICAL IDEAS IN HIS SFG}

This section is devoted to finding out the philosophical ideas in his SFG. In the following section we address an issue regarding on triangle: language, mind and the world

\section{Language, mind and world in Halliday's SFG}

Like other philosophers, Halliday (2000) draws a triangle in which lines connect "language", "mind" and "the world". The three lines represent relations that are keys to understand our place in reality. These relations in one or another way constitute the meaningfulness of language and are shown in figure 1.

Figure 1

On triangle: language, mind and the world within SFG

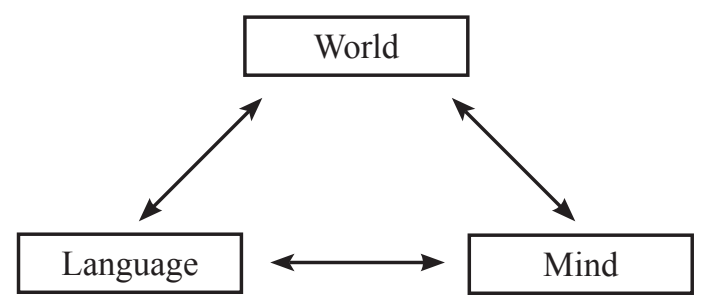

A number of phenomena and things in real world are reflected in our mind, and our mind encodes the goings on, creates a mental picture and invests meanings in language. Halliday understands and grasps the inter-relationship of language, mind and the world and applies it in his SFG, especially in three lines meanings of structure - the three metafunctions. The core idea of SFG is the three distinct modes of metafunction namely: Interpersonal, Textual and Experimental (ideational) metafunction, and each metafunction has its own system of choices. Then each choice results in a typical structure. Experimental (ideational) metafunction is the focus of our study as we stated in our introduction, and we dedicate all this section to discuss and analyze it. Experimental (ideational) metafunction is concerned with construing experience
- it is language as theory of reality, as a resource reflecting our real world. Martin (1997) takes an example in this work that let's imagine you look up at the sky with a number of things happening all the time. All these goings on and phenomena are reflected in our mind with a mental picture and construe a quantum of change as one process configuration. The output of this process is realized in lexicogrammar as one clause; for example: a kite is flying across the sky. With this we have turned our experience into meaning and into wording. In other words, we are concerned with the construal of human experience as a semantic system since language plays the central role not only in storing and exchanging experience but also in construing it. When interpreting this clause in the view of experimental metafunction, we analyze and label it in terms of Transitivity system including Participant, Process and Circumstance as follows:

(1)

\begin{tabular}{|c|c|l|}
\hline A kite & is flying & across the sky \\
\hline Actor & Pro: material & Circumstance \\
\hline
\end{tabular}

(Martin et al. 2009: 101)

(1) is an example of material Process in Transitivity system; "flying" is often used as an example of material clauses and "a kite" is interpreted as "Actor". The entity doing an action encoded in material process clauses above is labeled "actor". Halliday (1977) states that there is the identification of two grammatical classes based on meaning, on semantic function: verb, expressing (an) action, and noun, expressing (the) actor; the two combine to make up a piece of discourse. Here verb and noun are the names of classes; but they are defined by their functions - functions in transitivity, in the linguistic representation of actions and events and, naturally, the verb is identified first, the noun being then derived from it.

According to Halliday (2004), the transitivity system construes the world of experience into a manageable set of PROCESS TYPES. Each process type has its own model or schema for construing a particular domain of experience as a figure of a particular kind - a model such as the one illustrated above for construing signification: Token (usually) + Process (means) + Value 
(mostly).

It has come to our attention that the language structures each experience as a semantic configuration consisting of Process, Participant and Circumstance. These elements provide the framework for interpreting our experiment of what goes on. The concepts of Process, Participant and Circumstance are semantic categories which explain the most general way how phenomena of the real world are represented as linguistic structure. We will discuss their functions in a later section. Halliday (2004) offers the tripartite interpretation of Process, Participant and Circumstance as shown in Figure 2.

Figure 2

The tripartite interpretation of the Process, Participant and Circumstance in the experimental structure of the clause

(Halliday \& Matthiessen. 2004: 176)

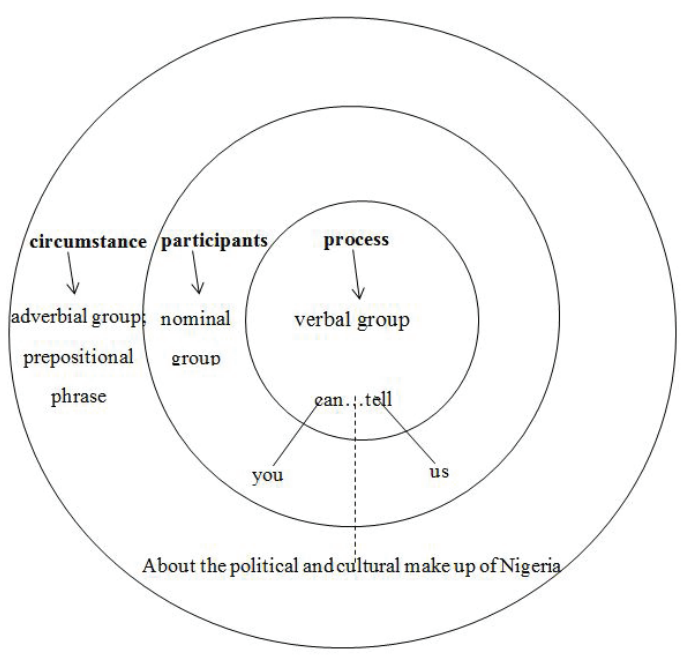

According to Halliday (2004) the transitivity system of a language construes experience into a small set of domains of meaning which differ according to the process itself and the nature of the participants involved in it. Processes play a central role in transitivity. The process centers on that part of the clause that is realized by the verbal group, but it can also be regarded as what 'goings-on' are represented in the whole clause. There are indeed six different process types identified by Halliday (1985): material, behavioural, mental, verbal, relational, and existential as follows:

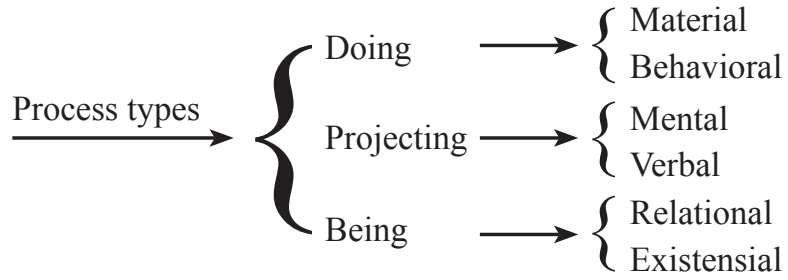

When interpreting a clause in line with experimental metafunction, Halliday represents our experience into different process types. We and many other scholars and researchers bear in mind a question why Halliday categorizes and labels six kinds like that and tries to find out a good reason for this matter. In our opinion, Halliday sees the inter-relationship of language, mind and world and applies it in his theory. There are three worlds in his theory: the outer world, the inner world and the abstract relationship world in experimental metafunction. The outer world is the physical world with natural phenomena, human beings' as well as entities' activities, and it is realized into Material, Existential and Behavioral processes. The inner world is the world of consciousness and awareness including processes of perception, cognition and affection, and it is realized into Mental and Verbal processes. The last world is the abstract relationship between human and nature, relationship among human beings and it is realized in Relational processes. The three worlds and their processes in grammar of experiment are shown in figure 3.

Figure 3

The three worlds and their processes in grammar of experiment

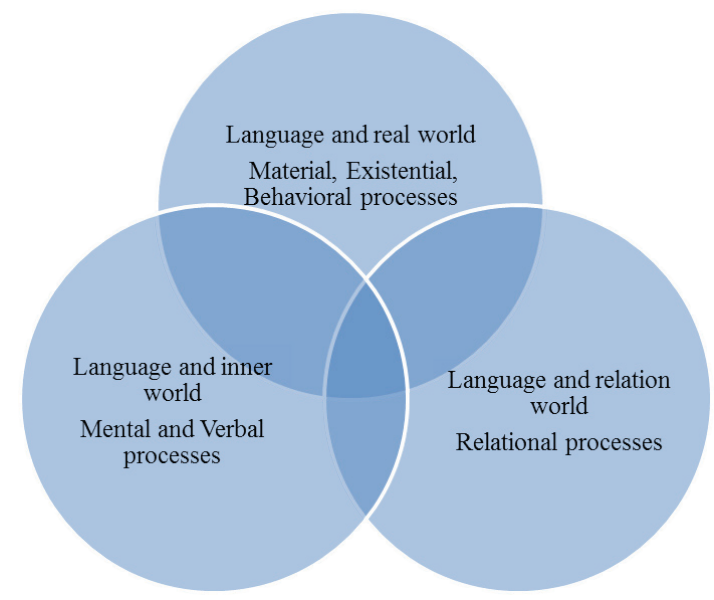


It can be seen from figure 3 that there are some overlaps and complementarities. For this, we turn back to the transitivity system. It is widely claimed that process types make distinctions of clause types. However, the issue arises when the type of process and clause conflicts. In some indeterminate cases, it is impossible to label a clause type as well as set a clear borderline among these processes and worlds due to the semantic conflict between clause and process types. To settle this conflict, we are in favor of semantic content. In other words, as the conflict between the process type and clause type occurs, we suggest making a decision to favor semantic clause interpretation. This helps analysts have a firm framework and evidence to determine the clause type and function. Moreover, Halliday (1994) broadened the traditional notion of transitivity to shift the focus away from entirely being marked on the verb. However, there is some considerable disagreement between the semantic and syntactic streams of information, and this causes some indeterminate cases for analysts (Gwilliams \& Fontaine. 2015, O'Donnell et al. 2009).

Let us consider the example of behavioural processes; these happen in a mixed category, formed by the overlap of the material, on the one side, and the mental or verbal on the other. Behaving is construed as a type of figure that (like the mental) typically has a conscious participant as the central role, and does not extend beyond this to a second participant; but, on the other hand, it does not project, and it has a time frame like that of the material. Thus behavioral processes lie in a fuzzy borderline (Halliday 2000). Let us consider the following example pairs:

(2a) I gave him this very cold stare.

(Sailing. 1951: 38)

(2b) I stared at him coldly.

(3a) He gave me a stare of newly-awakened surprise.

(Bronte. 1858:121)

(3b) He stared at me surprisingly.

Here at the syntactic ground, the grammar in (2a) is completely different from (2b) particularly the choices of process realized in each sentence but at the semantic ground, sentence (2a) is synonymous with (2b). It is clear that the semantics of the verb "gave" is not the problem and it commonly subsumes material processes. The difficulty here is due to the combination of the participant. Conceptually, at the semantic level of process, "gave" belongs to material processes (i.e. I gave him my notebook) but at the level of semantics of clause we have to determine whether (2a) and (3a) are material or behavioral processes. In these cases, with the view of semantics of clause, considering clauses as making and exchanging messages, it is suggested that (2a) and (3a) be Behavioral processes. It is clear that there are overlaps among these processes and worlds and these overlaps cause some indeterminacy for functional linguists to classify and categorize the process types in experiential metafunction. Halliday (2000) states that natural language is an indeterminate system and "the generalized categories that constitute language as a system as "order", rather than as randomness or "chaos" (let us say randomness rather than chaos, since chaos in its technical reading is also a form of order) - are typically not categorical: that is, they do not display determinate boundaries, fixed criteria of membership, or stable relationships from one stratum to another". (Halliday, 2000:562)

According to Halliday (1977) there are two main traditions in Western thinking about meaning: (i) one oriented towards logic and philosophy, with language seen as a system of rules;

(ii) one oriented towards rhetoric and ethnography, with language seen as resource. It is typically the logical-philosophical tradition that provides the background for work on knowledge representation and proposals for the knowledge base. Since the 50s, a link has been forged between this tradition and cognitivism under the general rubric of cognitive science. However, although it is less often referred to, the rhetoricalethnographic tradition is equally relevant to work on the modelling and representation of knowledge. Halliday adapts these two orientations but he is rather in favor of rhetoric and ethnography in his work. In fact, Halliday and Matthiessen (2000:417) states that "the two orientations differ in the metafunctional scope of their models of semantics. In the logico-philosophical orientation, 
meaning is closely associated with representation, reference, denotation, extension or 'aboutness', so the metafunctional scope is restricted to the ideational metafunction: semantics means ideational semantics"

\section{EMPIRICISM IN SFG}

It is widely recognized that there is a close connection between linguistics and philosophy. Any linguistic theorist must offer a comprehensive theoretical framework that is most widely employed in language description, particularly grammatical descriptions of entire languages. Halliday's theory firmly is based on a philosophical background and epistemology. Empiricism and rationalism are considered as the two dominant thoughts in epistemology and the dispute between empiricism and rationalism is as old as Aristole and Plato. Aristole and Plato took different views on the "paved" road to knowledge, namely empiricism and rationalism. Aristole believed in and applied empirical approach whilst Plato devoted himself to the rational one (Willis. 2009).

Rationalists generally develop their view in two ways. First, they argue that there are cases where the content of our concepts or knowledge outstrips the information that sense experience can provide. Second, they construct accounts of how reason in some form or other provides that additional information about the world. Empiricists present complementary lines of thought. First, they develop accounts of how experience provides the information that rationalists cite. Second, empiricists attack the rationalists' accounts of how reason is a source of concepts or knowledge (Kenny. 1986). The two famous ancient Greek philosophers, Chomsky (1988) and Halliday (1985) have different stances on their linguistic theories. Chomsky's generative linguistics takes rationalism as a central concept in his theory (See Nguyen Thien Giap 2014: 1-9) and Chomsky is considered as the most prominent contemporary defender of a form of rationalism. Chomsky (1988), along with his co-workers in linguistics and philosophy, has used "poverty of stimulus" consideration in support of the thesis that human knowledge of natural language is innate with two interesting issues; namely innate language acquisition device and universal grammar
(Chapman 2009: 71). On the contrary, Halliday's functional grammar theory is constructed on the foundation of empiricism. Halliday states that "each individual member of that species constructs the functioning mental map of their phenomenal world: of their experience of process, both what goes on out there and what goes on in the realms of their own consciousness" (Halliday 2000: 10). Halliday's stance on linguistic theory is expressed in these strongly empiricist words. Halliday also mentions cognition in his work but he explains that:

"We are saying that cognition "is" (that is,
can most profitably be modelled as) not
thinking but meaning: the "mental" map is in
fact a semiotic map, and "cognition" is just a
way of talking about language. In modelling
knowledge as meaning, we are treating it as
a linguistic construct: hence, as something
that is construed in the lexicogrammar.
Instead of explaining language by reference
to cognitive processes, we explain cognition
by reference to linguistic processes."
(Halliday, 2000:11).

It is safe to say that Halliday's systemic functional grammar views language as a social semiotic and a resource people use to accomplish their purposes by expressing meanings in context and making meaning central to his theory. Social semiotics has been strongly influenced by the work of Halliday (1978) Language as Social Semiotic. This work argues against the traditional separation between language and society, and exemplifies the start of a 'semiotic' approach, which broadens the narrow focus on written language in linguistics (Halliday 1978). For Halliday, languages evolve as systems of "meaning potential" (Halliday 1978:39) or as sets of resources which influence what the speaker can do with language, in a particular social context. For example, for Halliday, the grammar of the English language is a system organised for the following three purposes (areas or "metafunctions"). Halliday claims that "the internal organization of language is not arbitrary but embodies a positive reflection of the functions that language has evolved to serve in 
the life of social man" (Halliday 1976: 26). Based on three metafunctions or three lines of meanings suggested Halliday (1985) English clauses are analysis in terms of three aspects of meanings: the first is ideational meanings with transitivity system: Participant - Process - Circumstance, Interpersonal meaning with Mood, Modality and Textual with Theme and Rheme, Given and New.

First of all, Let us illustrate how English clauses are analyzed in terms of experimental (ideational) meaning in light of Halliday's functional grammar.

\begin{tabular}{|c|c|c|}
\hline Her hands & trembled & $\begin{array}{c}\text { slightly at her } \\
\text { work }\end{array}$ \\
\hline Behaver & Pro: behavioral & Cir: manner \\
\hline
\end{tabular}

(Lawrence. 1913: 158)

In their experimental meaning, Halliday (1985) takes processes or employs verbs as the core role of clauses and the other participants are labeled respectively. Halliday classifies processes into six categories namely material, mental, relational, behavioral, verbal, and existential.

Secondly, as for interpersonal meaning, English clauses are examined in functional perspective of Modality and Mood. It seems possible to recognize a simple but very basic aspect in terms of modality, one which considers clauses as utterances and examines them in light of social role function. An utterance often has an element of content and should be seen as exchange of information in a particular context. Let us consider the following example based on the framework (Mood-Residue) suggested by Halliday (1985).

\begin{tabular}{|c|c|c|c|}
\hline $\begin{array}{c}\text { Mr. Edgar's } \\
\text { coldness }\end{array}$ & depressed & me & exceedingly \\
\hline subject & predicator & complement & Adjunct \\
\hline Mood & Residue & & \\
\hline
\end{tabular}

(Bronte. 1858:127)

Finally, Textual meaning offers an interpretation of the clause in the function as a message with two part structures Theme and Rheme. Textual metafunction looks inwards to the text itself and sees clause as message (Halliday.1985). The following are examples of Theme-Rheme analysis.

\begin{tabular}{|c|c|c|}
\hline Mrs. Healthcliff's lip & quivered & Slightly \\
\hline Theme & Rheme & \\
\hline
\end{tabular}

\section{CONCLUSION}

Halliday describes language as a semiotic system and the philosophical foundation of Halliday's SFG is empiricism. Halliday is considered as a paradigmatic empiricist. The word paradigmatic is repeatedly mentioned in his work (2004). Halliday views language as social semiotic and highlights the concept of an act of meaning - of speech - as a symbolic action. In SFG, clauses can be analyzed on the basis of how they represent the world (experimental metafunction), how they enact social relations (interpersonal metafunction) and how they create a message (textual metafunction). Of the three metafunctions, the one that deals with the ability of language to convey some information about reality and construe experience through meaning at the lexico-grammar stratum is the experimental metafunction. The conceptualization of patterns of experience is represented in language by choices in the system of transitivity. The interrelationship of language, mind and world are construed into three worlds namely the outer world, the inner world and the abstract relationship world. In addition, it is clear that empiricism is readily available in SFG. Last but not least, SFG puts the act of meaning theory and text analysis in contexts in a higher position than form (structuration) and linguistic competence. Empiricism and SFG have been prominent in linguistics for a long time and it is hopeful they will be much more powerful in the future.

\section{REFERENCES}

Alexander, J. \& Weinberg, J. (2007). "Analytic Epistemology and Experimental Philosophy," Philosophy Compass, 2(1): 56-80.

Bloor, T. \& Bloor, M. (1995). The Functional Analysis of English: A Hallidayan Approach. Edward Arnold.

Bronte, E. (1858). Wuthering Heights. Harper \& Brothers, Publisher. New York. 
Chapman, S. \& Routledge, C. (2009). Key Ideas in Linguistics and the Philosophy of Language. Edinburgh University Press.

Chomsky, N. (1988). Language and Problems of Knowledge, Cambridge, MA: MIT Press.

Lawrance, D.H. (1913). Sons and Lovers. Wordsworth Classics.

Eggins, S. (1994), An introduction into Systemic Functional Linguistics. London and New York: Continuum.

Firth, J. R. (1948). "Sounds and prosodies." Transactions of the Philological Society. 127-152.

Gwilliams, L. \& Fontaine, L. (2015). "Indeterminacy in process type classification". Functional Linguistics 2015; 2:8. London: Springer.

Halliday, M.A.K. (1956). Grammatical categories in Modern Chinese. Transactions of the Philosophical Society. Philadelphia: American Philosophical Society.

Halliday, M.A.K. (1959). The language of the Chinese "Secret History of the Mongols". Oxford: Blackwell.

Halliday, M.A.K. (1976). Learning How to Mean: Explorations in the Development of Language. London: Edward Arnold.

Halliday, M.A.K. (1977). "Ideas about Language" Occasional Papers I. Applied Linguistics Association of Australia. Pp. 32-55.

Halliday, M.A.K. (1978). Language as social semiotic. The social interpretation of language and meaning. London: Edward Arnold.

Halliday, M.A.K. (1985). Introduction to functional grammar. London: Arnold.
Halliday, M.A.K. \& Matthiessen, C.M.I.M. (2000). Construing experience through meaning: a language-based approach to cognition, Open linguistics series, Continuum International.

Halliday, M.A.K. \& Matthiessen, C.M.I.M. (2004). An introduction to Functional Grammar. $3^{\text {rd }}$ ed. London, Arnold.

Hjelmslev, L. (1969). Prolegomena to a theory of language. Madison: University of Wisconsin Press.

Martin, J. R., Matthiessen, C. and Painter, C. (1997). Working with Functional Grammar. London: Edward Arnold.

O’Donnell, M., Zappavigna, M. \& C Whitelaw. (2009). "A survey of process type classification over difficult cases. In From Language to Multimodality: New Developments in the Study of Ideational Meaning”, ed. C Jones and E Ventola, 47-64. London: Continuum.

Kenny, A. (1986). Rationalism, Empiricism and Idealism.Oxford:OxfordUniversityPress.

Mwinlaaru, I. N. \& Xuan, W. W. (2016). “A survey of studies in systemic functional language description and typology". Functional Linguistics. Springer Open.

Nguyen Thien Giap. (2014). “N. Chomsky's Generative Linguistics: Philosophical Foundation and Epistemology". Journal of Science, Vietnam National University, Hanoi, Vol. 30, No. 4, p.1-9.

Sailing, J.D. (1951). The Catcher in the Rye. An imprint of Infobase Publishing. New York.

Willis, J. (2009). Qualitative Research Methods in Education and Educational Technology. Information Age Publishing Inc. USA. 